\title{
The Cost of Superconducting Magnets as a Function of Stored Energy and Design Magnetic Induction times the Field Volume
}

\author{
M. A. Green and B. P. Strauss
}

\begin{abstract}
By various theorems one can relate the capital cost of superconducting magnets to the magnetic energy stored within that magnet. This is particularly true for magnet where the cost is dominated by the structure needed to carry the magnetic forces. One can also relate the cost of the magnet to the product of the magnetic induction and the field volume. The relationship used to estimate the cost the magnet is a function of the type of magnet it is. This paper updates the cost functions given in two papers that were published in the early 1990's. The costs (escalated to 2007 dollars) of large numbers of LTS magnets are plotted against stored energy and magnetic field time field volume. Escalated costs for magnets built since the early 1990's are added to the plots.
\end{abstract}

Index Terms-Superconducting LTS Magnet Cost

\section{INTRODUCTION}

1 HE budgetary cost of a superconducting magnet system is often needed early in a project, in order to determine if the use of superconducting magnets is feasible. This report is an update of two reports written by S. J. St. Lorant and this author [1]-[2]. This report presents a method for making a budgetary cost estimate of a superconducting magnet system. The method used in this report is plotting the cost of superconducting magnet (escalated to 2007 dollars) against a scaling parameter. Once the cost data has been plotted against the scaling factor a cost equation can be fitted to the data. This method was used in the two reports from the early 1990 's. One of the difficulties of this type of cost estimate is choosing the appropriate scaling parameter.

For superconducting magnets, the appropriate scaling factor may be stored energy. This scaling factor is certainly appropriate for magnets where the cost of the magnet is dominated by stress. A second scaling factor is the average magnetic induction times the volume of the field in the useful field region. For simplicity the two scaling parameters given above were chosen this report. Stored energy has been used as a scaling parameter since the early 1970 's, because cost is related directly to pressure force in the magnet [3]-[6].

Manuscript received 27 August 2007. This work was supported by the Lawrence Berkeley Laboratory and the Office of Science, U.S. Department of Energy under Contract No. DE-AC02-05CH11231.

M. A. Green is from the Lawrence Berkeley National Laboratory, Berkeley CA 94720, USA, E-mail: magreen@1bl.gov.

B. P. Strauss is from the Office of Science, US Department of Energy, Washington DC 20020, USA. E-mail: Bruce.Strauss@science.doe.gov

\section{Cost CAlculation Methodology}

The system characteristics were obtained from a systematic perusal of the published literature, which included technical reports circulated among interested institutions, and confirmed by direct inquiry. For the costs, the "Technical Proposal" or its equivalent was the usual starting point, followed by an actual tracking of the project costs through information obtained from the funding agency or its representative organ. In the US, this is often simply a matter of identifying the appropriate government publication; abroad, it requires a network of helpful correspondents and friendly reciprocity. In spite of the disparity of the sources, the raw cost data were usually reliable to about 15 or 20 percent.

In most cases, the magnet systems were assumed to be completed on the date of its first successful acceptance test. The purpose of this artificial cut-off is that it is to better isolate the construction costs from subsequent commissioning changes, which tend to have a life of their own and hence associated costs of their own. The actual project cost was then converted to 2007 dollars using the composite escalation index for the fabrication of industrial equipment. The escalation factor used from earlier times is shown in Fig. 1. Foreign project costs were converted to US currency using the exchange rate at the time of fabrication and then they were escalated in the same manner as domestic projects.

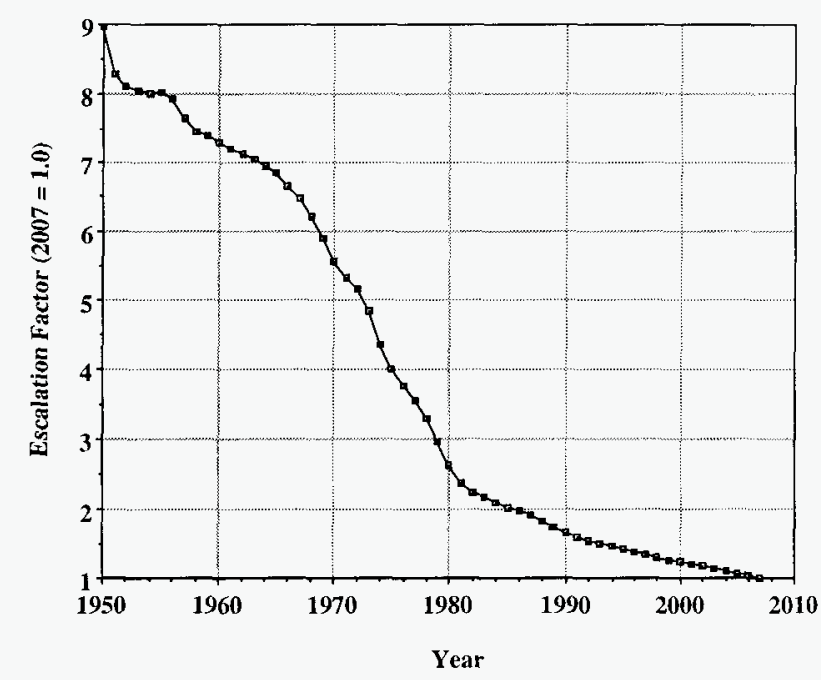

Fig. 1. The Escalation Factor used to Escalate Costs incurred in Earlier Years (See Reference [7] and multiply by 1.34 for escalation to 2007 dollars.) 


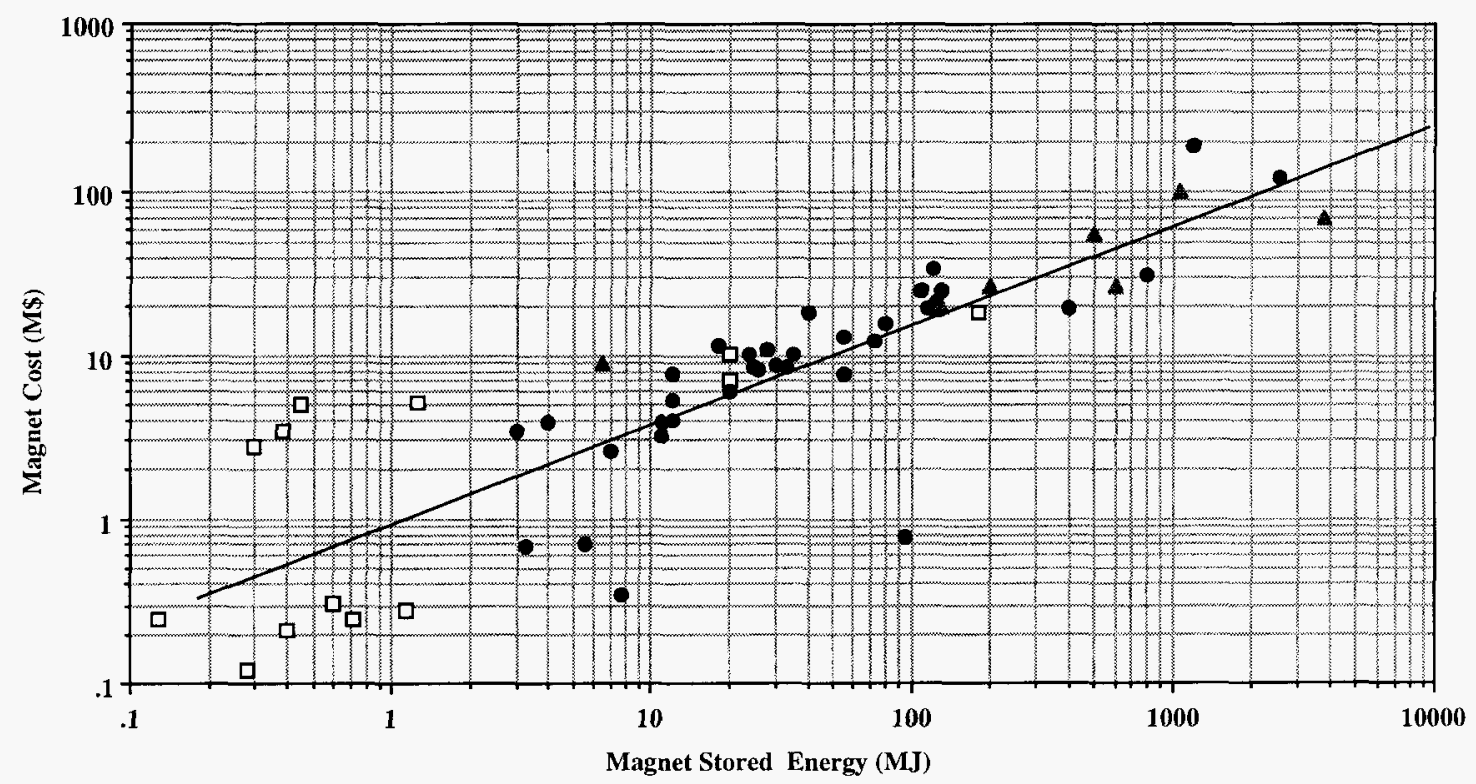

Fig. 2. Superconducting magnet costs (M\$) versus stored energy (MJ) for solenoid magnets (closed circles), dipole and Quadruple magnets (open squares) and toroid magnets (closed triangles). The line is a plot of equation 1 , which can used to calculate the cost of all magnets.

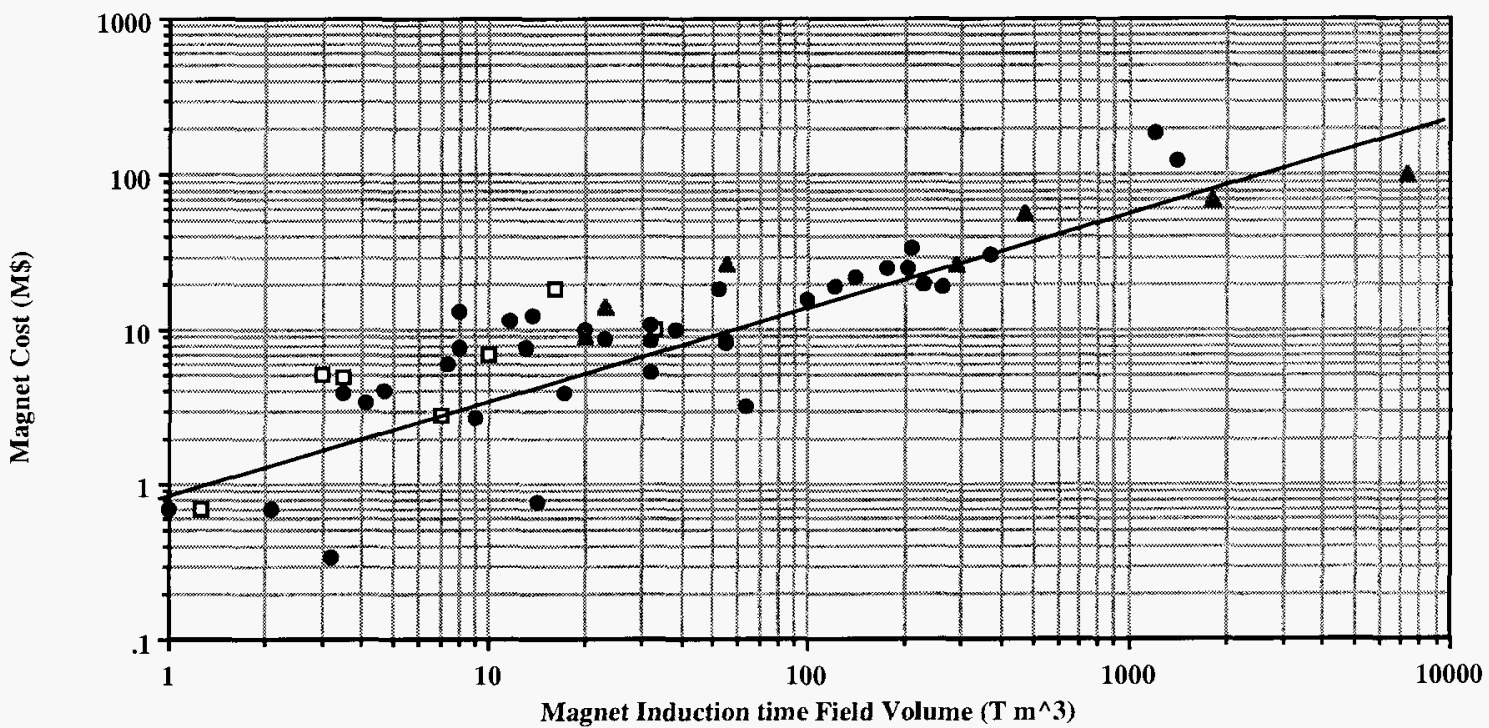

Fig. 3. Superconducting magnet costs (M\$) versus induction times field volume (T-m $\mathrm{m}^{-3}$ ) for solenoid magnets (closed circles), dipole and Quadruple magnets (open squares) and toroid magnets (closed triangles). The line shown in the figure is a plot of equation 2, which can be used to calculate the cost of all magnets.

Fig. 1 shows that producer price inflation rates in the United States have been relatively low since 1980 . The rate of inflation was much higher between 1967 and 1981. The period from 1981 on represents a shift in production from the United States and Europe to countries with much lower production costs. To a smaller extent this is happening in Japan as well. Where production has remained in countries with high labor rates, the production as become more efficient and in some cases the part production has been outsourced to lower cost regions of the globe.

\section{The Results of the Magnet Cost Analysis}

The escalated costs of magnets (in M\$) are plotted on a loglog plot against the magnet stored-energy (MJ) in Fig 2. The escalated cost of magnets (in M\$) is plotted on a log-log plot against the magnetic induction times field volume $\left(T-\mathrm{m}^{3}\right)$ in Fig. 3. Three magnet types are plotted in Fig. 2. and Fig. 3.
These magnets are solenoid magnets (the open circles), dipole and quadrupole magnets (closed squares) and toroid magnets (closed triangles). All costs are given in 2007 dollars. Cost fitting lines (least squared fits) are shown for all magnets, solenoid magnets, and toroid magnets.

The cost equations for all magnets in Fig. 2 and Fig. 3. take the following form;

and

$$
\mathrm{C}(\mathrm{M} \$)=0.92[\mathrm{E}(\mathrm{MJ})]^{0.60}
$$

$$
\mathrm{C}(\mathrm{M} \$)=0.80\left[\Omega\left(\mathrm{T}-\mathrm{m}^{-3}\right)\right]^{0.60}
$$

where $\mathrm{C}$ is the magnet cost; $\mathrm{E}$ is the magnet stored-energy at its design current; and $\Omega$ is the magnetic field volume times the average magnetic induction at its design current.

When solenoid magnets were separated from the other magnets the cost equations take the following form; 


$$
\mathrm{C}(\mathrm{M} \$)=0.95[\mathrm{E}(\mathrm{MJ})]^{0.67}
$$

and

$$
\mathrm{C}(\mathrm{M} \$)=0.55\left[\Omega\left(\mathrm{T}-\mathrm{m}^{-3}\right)\right]^{0.67}
$$

where $\mathrm{C}, \mathrm{E}$, and $\Omega$ are defined as they were before.

When toroid magnets were separated from the other magnets the cost equations take the following form;

and

$$
\mathrm{C}(\mathrm{M} \$)=2.04[\mathrm{E}(\mathrm{MJ})]^{0.50}
$$

$$
\mathrm{C}(\mathrm{M} \$)=2.01\left[\Omega\left(\mathrm{T}-\mathrm{m}^{-3}\right)\right]^{0.50}
$$

where $\mathrm{C}, \mathrm{E}$, and $\Omega$ are defined as they were before.

When dipole and quadrupole magnets were separated from the other magnets the cost equations take the following form;

$$
\mathrm{C}(\mathrm{M} \$)=1.05[\mathrm{E}(\mathrm{MJ})]^{0.65}
$$

and

$$
\mathrm{C}(\mathrm{MS})=1.01\left[\Omega\left(\mathrm{T}-\mathrm{m}^{-3}\right)\right]^{0.65}
$$

where $\mathrm{C}, \mathrm{E}$, and $\Omega$ are defined as they were before.

There is a great deal of scatter in the costs in Fig. 2 and Fig.3. There is not a clear well defined line that can be used to accurately estimate costs given magnet stored-energy or average bore induction time field volume in the magnet bore. There is a general trend that cost will go up with stored energy and with field volume times average induction. There are lots of reasons for variation in cost. A magnet of a given stored energy may have a smaller volume where the field is concentrated. Such a magnet will have a smaller cryostat, which will reduce the cost.

A high field magnet may require the use of a different conductor or even more conductor, which will affect the cost of the magnet. In most of the magnets shown in Fig. 2 and Fig. 3 the conductor will represent ten to twenty percent of the cost. A niobium tin magnet will have a higher cost related to the conductor. HTS magnets are not included in Fig. 2 and Fig. 3. The cost of most of the HTS magnets built to date is dominated by the cost of the conductor.

\section{COSTS FOR DETECTOR MAGNETS}

The same methodology was applied to detector magnets that are commonly used in high-energy physics experiments. The magnets in the sample have stored magnetic energies as low as $3.3 \mathrm{MJ}$ (for a small magnet) to $2.56 \mathrm{GJ}$. The magnets have magnetic induction time volume that range from $1 \mathrm{~T}-\mathrm{m}^{3}$ to as high as about $7350 \mathrm{~T}-\mathrm{m}^{3}$. Most of the detector magnets analyzed are solenoid magnets. Those that aren't are toroid magnets. Many of the detector magnets use aluminumstabilized conductor; but a number of the smaller magnets use copper stabilized conductor. Fig. 4 is a plot of magnet cost versus magnet stored-energy. Fig. 5 . is a plot of magnet cost versus magnetic induction times the field volume. Fig 6 . is a plot of magnet cost versus magnet mass.

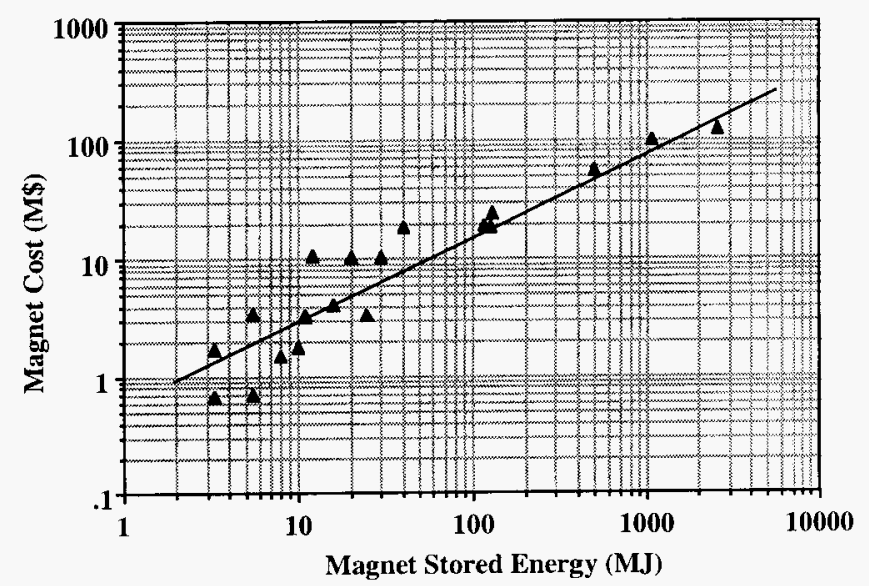

Fig. 4. The Cost of Detector Magnets as a Function of Magnet Stored Energy

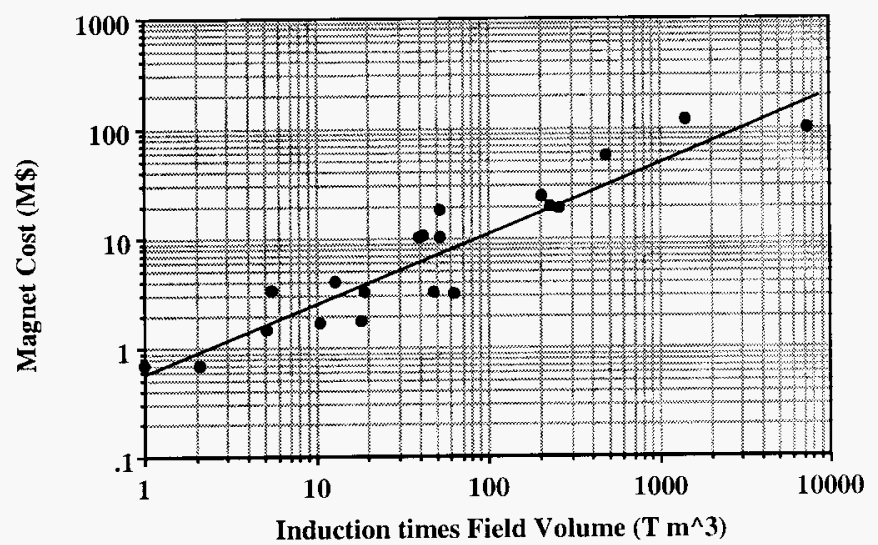

Fig. 5. Detector Magnet Cost as a Function of Induction times Field Volume

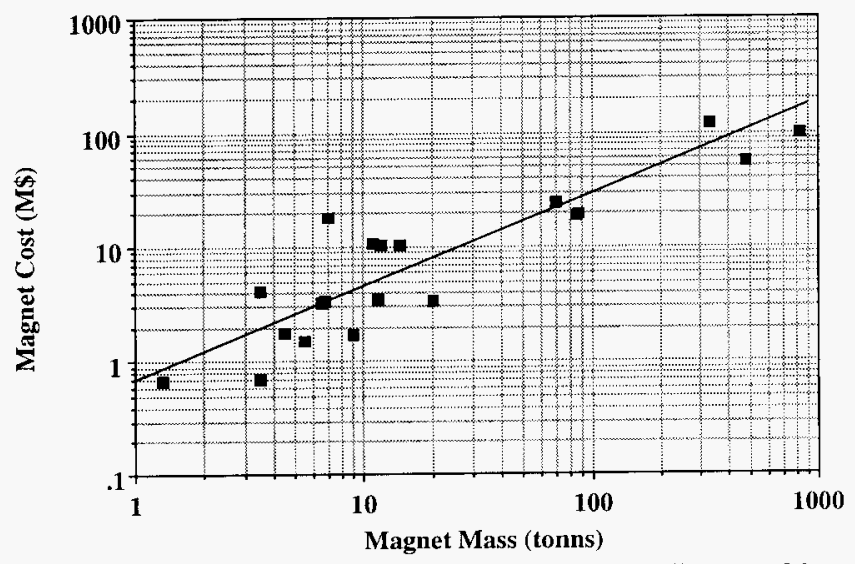

Fig. 6. The Cost of Detector Magnets as a Function of Overall Magnet Mass

The cost equations for detector magnets in Fig. 4, Fig. 5, and Fig. 6 take the following form;

$$
\begin{aligned}
& \mathrm{C}(\mathrm{M} \$)=0.58[\mathrm{E}(\mathrm{MJ})]^{0.69}, \\
& \mathrm{C}(\mathrm{M} \$)=0.55\left[\Omega\left(\mathrm{T}-\mathrm{m}^{-3}\right)\right]^{0.65},
\end{aligned}
$$

and

$$
\mathrm{C}(\mathrm{M} \$)=0.75[\mathrm{M}(\text { tons })]^{0.80} \text {, }
$$

where $\mathrm{C}$ is the magnet cost; $\mathrm{E}$ is the design magnet stored energy $\Omega$ is the design magnetic field volume times the average magnetic induction; and $M$ is the magnet cold mass and cryostat mass given in metric tons. 
The plots given in Fig. 4, Fig. 5, show less scatter than the plots given in Fig. 2 and Fig. 3. The reason for this is that detector magnets are more alike than most other types of superconducting magnets. When one compares Fig. 6 with Fig. 4 and Fig. 5, one sees that the scatter is roughly the same. Fig. 6 was included to test the thesis that what one really pays for in a superconducting magnet is magnet mass. This is partially true, but mass is only part of the picture. In all of the detector magnets shown in Fig. 4, Fig. 5, and Fig. 6, the superconductor represents less than twenty percent of the magnet cost. Most of the cost is in the labor needed to fabricate the magnet.

\section{REFRIGERATION COST}

The magnet costs given in Figs. 1 through 6 for the most part do not include the capital cost of refrigeration. The cost of refrigeration in 1991 was included in [1]. For more recent refrigeration costs one should look at a paper presented at the Cryogenic Engineering Conference in Chattanooga TN in 2007 [8]. The costs refrigerators and coolers are based on a temperature of either $4.5 \mathrm{~K}$ or $4.2 \mathrm{~K}$.

The capital cost of large $(>10 \mathrm{~W}) 4.5 \mathrm{~K}$ refrigerators is given by the following expression;

$$
C(M \$)=2.60[R(k W)]^{0.7}
$$

where is the refrigerator capital cost given in millions of US dollars and $\mathrm{R}$ is the design refrigeration (given in $\mathrm{kW}$ ) at all temperatures normalized to a temperature of $4.5 \mathrm{~K}$. A similar equation can be used for small coolers $(<10 \mathrm{~W})$ that produce refrigeration at $4.2 \mathrm{~K}$ and at $50 \mathrm{~K}$. The cooler cost equation takes the following general form;

$$
\mathrm{C}(\mathrm{k} \$)=40[\mathrm{R}(\mathrm{kW})]^{0.5}
$$

where is the refrigerator capital cost given in thousands of US dollars and $\mathrm{R}$ is the design refrigeration at $4.2 \mathrm{~K}$ given in watts. If the cooling on the upper stages of a cooler were normalized to $4.5 \mathrm{~K}$, the cooler cost equation would look more like equation 12. For example, a cooler that produces $1.8 \mathrm{~W}$ of cooling at $4.5 \mathrm{~K}$ will produce $\sim 40 \mathrm{~W}$ of cooling at $50 \mathrm{~K}$. The equivalent $4.5 \mathrm{~K}$ refrigeration for such a cooler would be about $5 \mathrm{~W}$. The cost of such a refrigerator using equation 12 would be about $64 \mathrm{k} \$$, where is equation 13 is used, the cost would be about $54 \mathrm{k \$}$.

\section{DISCUSSION OF THE RESULTS}

The use of budgetary cost equations similar to the ones given in this report is fraught with difficulties. The scatter in the data is large. While the authors have included dipoles and quadrupoles in their data set, it may not be very useful to use the dipole and quadrupole cost equations, because the scatter in the data is so large. The scatter in the data for detector magnets is small enough that it is useful to use the detector magnet cost equation, but the contingency must be large (up to fifty percent). There are other cost equations around besides the ones given in this report. In general, these equations suffer from the same difficulties as the ones given here. There is no substitute for a good bottoms-up cost estimate.

The cost equations given in this report cannot be applied to magnets made with HTS conductor, particularly when this conductor is used at temperatures above $10 \mathrm{~K}$. At this time, the cost of magnets made with HTS conductor will be dominated by the cost of the conductor. The cost saving in the refrigeration of HTS magnets is not impressive. The cost of cooling an HTS magnet at $30 \mathrm{~K}$ is not very different from the cost of cooling a $\mathrm{Nb}$-Ti magnet at $4.5 \mathrm{~K}$. An order of magnitude more refrigeration is required to cool an HTS magnet at $30 \mathrm{~K}$ as compared to an LTS magnet at $4.5 \mathrm{~K}$.

\section{REFERENCES}

[1] M. A. Green, R. A. Byrns and S. J. St. Lorant, "Estimating the Cost of Superconducting Magnets and the Refrigerators that Keep the Cold," Advances in Cryogenic Engineering 37, p. 637, Plenum Publishing, New York NY, (1991).

[2] M. A. Green and S. J. St. Lorant, "Estimating the Cost of Large Superconducting Thin Solenoid Magnets," Advances in Cryogenic Engineering 39, p. 271, Plenum Publishing, New York NY, (1993).

[3] J. R. Powell, "Design and Economics of Large DC Fusion Magnets," Applied Superconductivity Conference Proceedings Annapolis MD p346, IEEE Pub. No. 72CH0682-5-TABSC (1972)

[4] M. S. Lubel, H. M. Long, J. N. Luton, and W. C. T. Stoddart, "The Economics of Large Superconducting Toroidal Magnets for Fusion Reactors," Applied Superconductivity Conference Proceedings Annapolis MD, p341, IEEE Pub. No. 72CH0682-5-TABSC (1972)

[5] B. M. Winer and J. Nicol, "An Evaluation of Superconducting Energy Storage," IEEE Transactions on Magnetics MAG-17, No. 1, p 336, (1981)

[6] R. W. Boom, "Superconducting Energy Storage for Diurnal Use by Electric Utilities," IEEE Transactions on Magnetics MAG-17, No. 1, p $340,(1981)$

[7] American Inst. Economic Resources, Economic Education Bulletin November 1996, (Escalation since 1996 has been about 34 percent.)

[8] M. A. Green, "The Cost of Helium Refrigerators and Coolers for Superconducting Devices as a Function of Cooling at $4.5 \mathrm{~K}$," submitted to Advances in Cryogenic Engineering 53, AIP Press, Melville NY, (2008). 